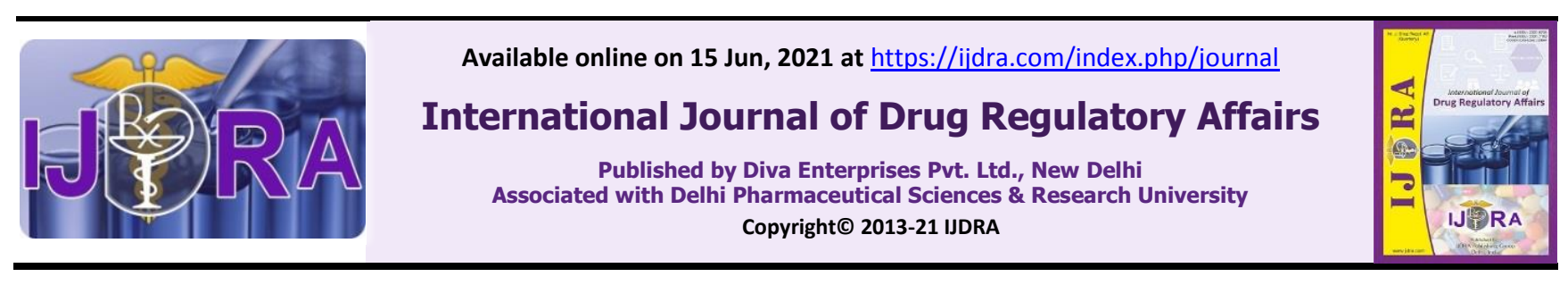

Review Article

OpenOAccess

\title{
FDA's drug regulatory pathways, its development strategies and regulatory considerations
}

\author{
Iva Dhulia*, Himani Patel, Narendra Chauhan, Nidhi Pardeshi \\ Department of Regulatory Affairs, Isazi Pharma and Techno Consultancy Private Limited, Vadodara, Gujarat, India - 390007
}

\begin{abstract}
People who are interested in drug development may be aware that New Drug Applications (NDA) and Abbreviated New Drug Applications (ANDA) are 2 of the FDA's regulatory pathways for how prescription drugs can be approved and ultimately reach the market. In basic terms, NDAs are for new drugs that have not yet been approved and ANDAs are for generic products.

NDA, also called 505 (b)(1), is the format that manufacturers use to bring a formal proposal to the FDA that a new drug should be approved and made available for use by patients in the United States. Under 505(b)(1), all investigations supporting safety and effectiveness, both clinical and nonclinical, are conducted by or on behalf of the sponsor. The other pathway is termed as abbreviated because preclinical and clinical trials are not required. The abbreviated approval pathways are described in section 505(j) and 505(b)(2) of the FD\&C Act and known as ANDA and Hybrid applications respectively. Hatch-Waxman amendments in 1984 provided for a suitability petition that allows the application of ANDA for a drug product that differs from the RLD in its dosage form, route of administration, strength, or active ingredient (in a product with more than one active ingredient). The differences allowed for suitability petition and 505(b)(2) application are same but ANDA filed through suitability petition can contain only those differences that do not need clinical evidence for efficacy and safety. This article identifies considerations to help potential applicants determine the appropriate submission pathway, its development strategies to support approval under those pathways.
\end{abstract}

Keywords: FDA, New Drug Applications (NDA), Abbreviated New Drug Applications (ANDA), IND, Petitioned ANDA, 505(b)(2) application, RLD

Article Info: Received 14 Apr. 2021; Review Completed 02 Jun. 2021; Accepted 04 Jun. 2021

Cite this article as:

Dhulia I, Patel H, Chauhan N, Pardeshi N. FDA's drug regulatory pathways, its development strategies and regulatory considerations. Int J Drug Reg Affairs [Internet]. 2021 Jun 15 [cited 2021 Jun 15]; 9(2):6-15. Available from: http://ijdra.com/index.php/journal/article/view/460

DOI: $10.22270 /$ ijdra.v9i2.460

*Corresponding author

\section{Introduction}

A fundamental question for any drug development program is which regulatory pathway to pursue. The answer is important to determine early on, because it dictates the scope of clinical and nonclinical studies that need to be conducted and how the marketing application will be presented to regulators. Before considering development pathway, below questions need to be answered first:

- Is the active ingredient(s) novel, or is it the same or very similar to another drug that has already been approved?

- If the active ingredient is the same, is there a reference listed drug product (RLD)?

- Are there other differences between proposed product and the approved product, such as the route of administration, which could impact safety or effectiveness?
- Is proposed product being developed for the same indication as the approved drug?

- Are there data from the approved product or published literature that you can rely upon to limit the need for (or scope of) your own studies?

- If you rely on external data, how does that impact market exclusivity for your own product?

These are certainly not the only questions that need to be asked - far from it - but they do help illustrate one key point. Asking the right questions up front naturally leads to a cascade of other important considerations. The ability to ask the right questions, obtain accurate responses, and thoughtfully apply the information that you gather to your program provides a rational and deliberate approach to choosing an appropriate drug development pathway. (1) 
Section 505 of the Federal Food, Drug, and Cosmetic (FD\&C) Act, describes different routes for obtaining approval of two broad categories of drug applications: new drug applications (NDAs) and abbreviated new drug applications (ANDAs).

NDAs and ANDAs can be divided into the following four categories:

- A "stand-alone NDA" is an application submitted under section 505(b)(1)
- A 505(b)(2) application is an NDA submitted under section 505(b)(1)

- An ANDA is an application for a duplicate under section 505(j) of the FD\&C Act

- A petitioned ANDA is a type of ANDA (2)

We will discuss all the regulatory pathways in details below.

2. Submission through the Appropriate Approval Pathway

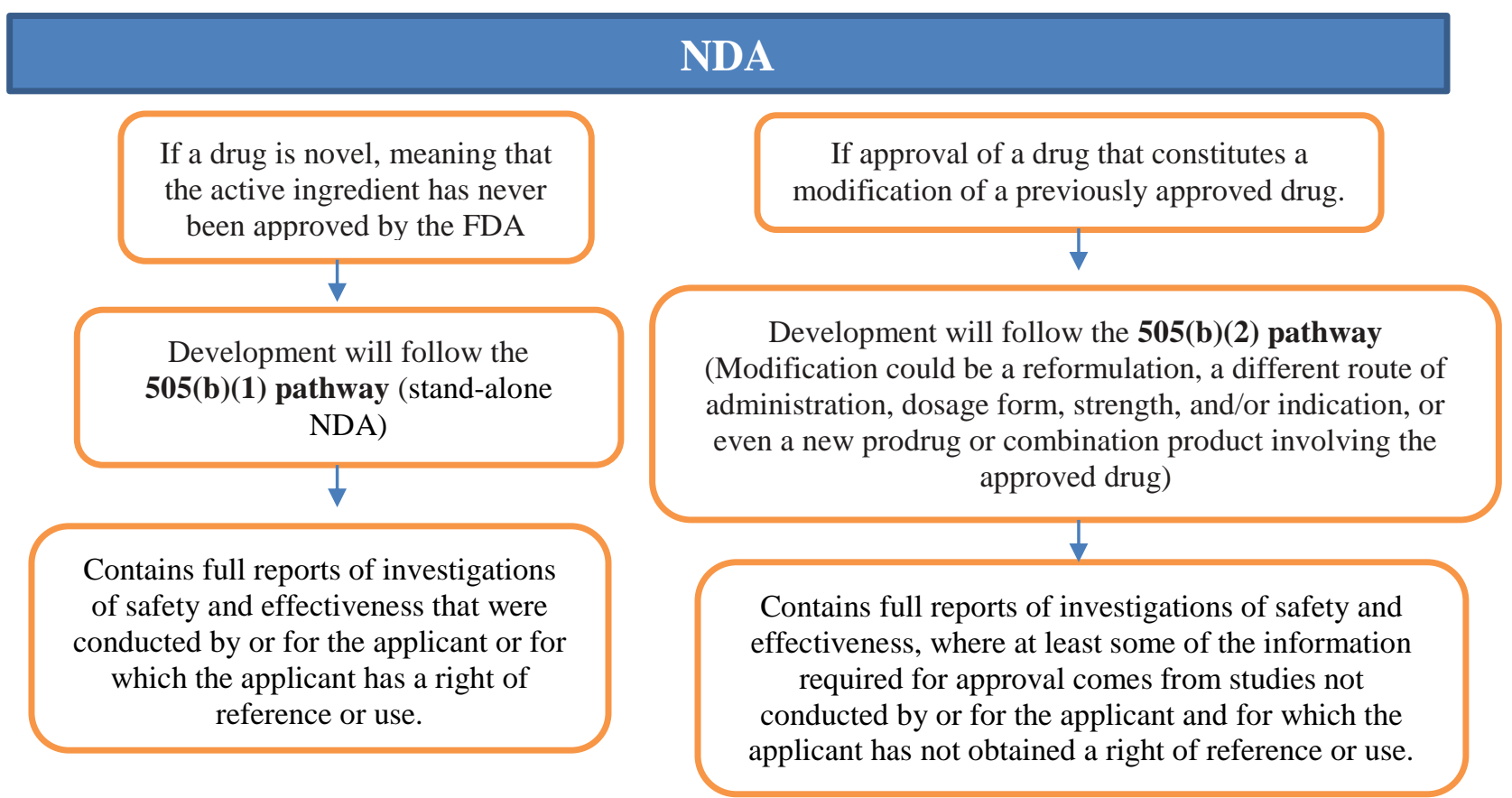

Figure 1. Flow Chart showing New Drug Application Pathway $(1,2)$

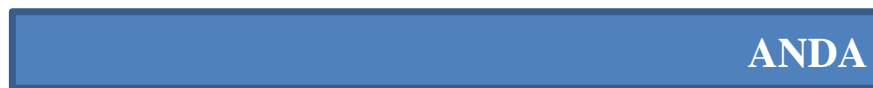

ANDA relies on FDA's finding of safety and effectiveness of approved drug product, i.e., the reference listed drug (RLD) ANDAs contain information to show that the proposed generic product:

(1) is the same as the RLD with respect to the active ingredient(s), conditions of use, route of administration, dosage form, strength, and labeling (with certain permissible

If drug product that has the same active ingredient(s), dosage form, strength, route of administration, and conditions of use as a listed drug

Development will follow the $\mathbf{5 0 5}(\mathbf{j})$ pathway

If drug product that differs from the RLD in its dosage form, route of administration, strength, or active ingredient (in a product with more than one active ingredient)

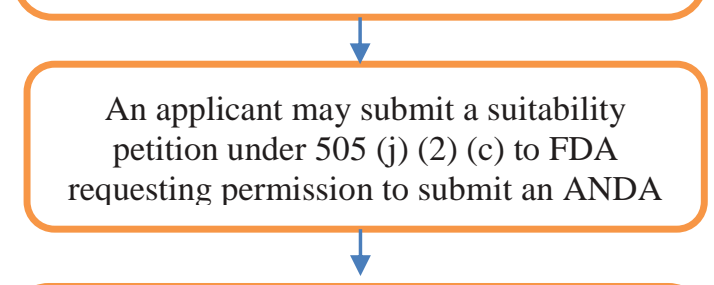

FDA will approve a suitability petition if it determines, that studies are not necessary to establish the safety and effectiveness of the proposed drug product.

Figure 2. Flow Chart showing Abbreviated New Drug Application Pathway $(1,2)$

\section{New Drug Applications}

505 (b) (1) Applications (Stand-Alone NDA)
A "stand-alone NDA" is an application submitted under section 505(b)(1) and approved under section 505 (c) of the FD\&C Act that contains full reports of 
investigations of safety and effectiveness that were conducted by or for the applicant or for which the applicant has a right of reference or use. (2)

\section{Investigational New Drug Application (IND)}

The IND is the launching point for clinical investigations in the United States and is an essential step along the path toward getting a new drug on the market. From the FDA's perspective, the purpose of an initial IND submission is to present the FDA with the general investigational plan and protocols for specific human studies. It is also meant to provide preliminary support for the safety, efficacy, and quality of the investigational product. This typically includes evidence from nonclinical studies and published literature, as well as initial product quality parameters and manufacturing information.

Following the initial submission, IND updates are provided by the Sponsor and may include protocol amendments, IND safety reports, information amendments, and annual reports. The purpose of these updates is to inform the FDA about new safety findings, the results of clinical investigations, important changes to manufacturing or quality processes, and other program related information.

Data collected during the IND phase of the development program will become part of the NDA. However, the NDA is much more comprehensive than the IND and is expected to provide very detailed information about the drug. This includes primary data, reports, and summaries of the results of the nonclinical and clinical studies, analyses related to the body's effect on the drug and the drug's effect on the body (PK/PD), characterization of the drug's ingredients and impurities (including any potential toxicities), and a description of all manufacturing processes and quality control parameters. $(3-4)$

\section{505 (b) (2) Applications}

It takes a great deal of time and resources for a manufacturer to complete all the necessary requirements to submit a successful NDA to the FDA for review. The 505 (b)(2) pathway provides manufacturers who have certain types of drugs with an opportunity to acquire FDA approval without performing all the work that's required with an NDA. These drugs are not strictly generics, but are often not entirely novel new molecular entities either. (5)

A 505(b)(2) application is one for which one or more of the investigations relied upon by the applicant for approval "were not conducted by or for the applicant and for which the applicant has not obtained a right of reference or use from the person by or for whom the investigations were conducted"

\section{Type of information on which an applicant can rely on:}

\section{Published literature:}

An NDA will be a 505(b)(2) application if any of the specific information necessary for approval is obtained from literature or from another source to which the applicant does not have a right of reference, even if the applicant also conducted clinical studies to support approval.

Note, however, that this does not mean any reference to published general information (e.g., about disease etiology, support for particular endpoints, methods of analysis) or to general knowledge causes the application to be a 505(b)(2) application. Rather, reference should be to specific information (clinical trials, animal studies) necessary to the approval of the application.

The Agency's finding of safety and effectiveness for an approved drug:

Only to the extent that the proposed product in the 505(b)(2) application shares characteristics (e.g., active ingredient, dosage form, route of administration, strength, indication, conditions of use) in common with the listed drug.

\section{Applications that can be submitted as a 505(b)(2) application}

New chemical entity (NCE)/new molecular entity $(N M E)$ :

For an NCE, this data is likely to be derived from published studies, rather than FDA's previous finding of safety and effectiveness of a drug.

\section{Changes to previously approved drugs:}

For changes to a previously approved drug product, an application may rely on the Agency's finding of safety and effectiveness of the previously approved product, coupled with the information needed to support the change from the approved product. The additional information could be new studies conducted by the applicant or published data.

\section{Content of 505(b)(2) Applications}

A 505(b)(2) application should include the following:

- Identification of those portions of the application that rely on information the applicant does not own or to which the applicant does not have a right of reference

- If the 505(b)(2) seeks to rely on the Agency's previous finding of safety or efficacy for a listed drug or drugs, identification of any and all listed drugs by established name, proprietary name (if any), dosage form, strength, route of administration, name of the listed drug's sponsor, and the application number.

- Information with respect to any patents that claim the drug or the use of the drug for which approval is sought. This patent information will be published in the Orange Book when the application is approved.

- Information required if the applicant believes it is entitled to marketing exclusivity.

- A patent certification or statement as required under section 505(b)(2) of the Act with respect to any relevant patents that claim the listed drug and that claim any other drugs on which the investigations relied on by the applicant for approval of the 
application were conducted, or that claim a use for the listed or other drug.

- If an application is for approval of a new indication, and not for the indications approved for the listed drug, a certification so stating.

- A statement as to whether the listed $\operatorname{drug}(\mathrm{s})$ identified above have received a period of marketing exclusivity. If a listed drug is protected by exclusivity, filing or approval of the 505(b)(2) application may be delayed.

- A Bioavailability/Bioequivalence (BA/BE) study comparing the proposed product to the listed drug (if any).

- Studies necessary to support the change or modification from the listed drug or drugs (if any). (6)

\section{5(b)(2) Program Development Strategies}

505(b)(2) development can be challenging but offers tremendous opportunity for sponsors. When planning to create a 505(b)(2) development program, you must determine how the new drug product is different and similar to the innovator drug, especially in relation to its pharmacokinetic (PK) characteristics. From there, you can leverage all information relevant to the new drug product by creating a "PK bridge" linking the in vivo performance of the new drug product to that of the innovator drug product. Understanding how to best link the two products is an essential step in maximizing the full streamlining capability of the 505(b)(2) approach.

Having a robust PK development plan in your 505(b)(2) strategy allows for rapid advancement of the regulatory approval process at minimal cost. For example, when considering oral products, PK studies that address bioequivalence, bioavailability, multiple-dose PK, and food effect can often meet the minimum PK requirements.

\section{Navigating the 505(b)(2) Submission Process}

There are four main components to be aware of when navigating the 505(b)(2) submission process which are: candidate identification, candidate assessment, product planning and the pre-IND meeting.

\section{Candidate Identification}

Identifying drug products that are suitable for the 505(b)(2) process is an essential first step in minimizing the risk of failure and taking advantage of this more streamlined route to approval. Often this can be done with a few nonclinical studies. Early in the Phase 1 program, it is important to keep in mind that the PK profile of the new product does not have to mimic that of the innovator product exactly. The PK profile should be "as favorable" as that of the innovator product, taking into consideration the intended use of the new product. That way a 505(b)(2) candidate should present a low development risk and an increased potential payoff by differentiating itself from the rest of the market.

\section{Candidate Assessment}

In order to reduce the risk of costly errors, candidate assessment prior to development is vital and can establish the value proposition of a product concept for investors. A proper candidate for a 505(b)(2) application should have scientific, medical, regulatory, and commercial viability.

Scientific Viability: Evaluating scientific aspects of the candidate, including stability and preparation of the product, scalability of manufacturing, and availability and affordability of active and inactive ingredients.

Medical Viability: Establishing a clear niche for the product, such as a unique solution to an unmet need. In addition, the risk/benefit and appeal to the proposed patient population should be considered.

Regulatory Viability: Determining the availability of clinical trial data or other data that may be used to gain approval. Distinguishing information that could be presented on labeling for future promotional activity should also be considered.

Commercial Viability: Determining the availability of a viable market for the product and assessing the potential for future competition or substitution, as well as what is needed to ensure reimbursement and optimal pricing.

\section{Product Planning}

During the product planning stage, a potential developer should assess ways to incorporate existing data into their development strategy. In addition, the options for market exclusivity should be considered. Some products may qualify for distinctions such as orphan drug exclusivity (seven years), new chemical entity (NCE) exclusivity (five years), "other" exclusivity (three years, if certain criteria are met), and pediatric exclusivity (six months added to existing exclusivity/patents). While NCE exclusivity is often thought of only for 505(b)(1) drugs, it is also possible to gain NCE exclusivity via the 505(b)(2) pathway.

\section{5(b)(2) Pre-IND Meeting}

The pre-investigational drug application involves a pre-IND meeting with the FDA before the eventual IND filing. The pre-IND process for the 505(b)(2) vs. 505(b)(1) pathways differs greatly. Major distinctions include:

Order of steps: Unlike the 505(b)(1) process, 505(b)(2) is initiated with the pre-IND meeting, moving into formulation development and additional studies (if deemed necessary), and concluding with the IND filing.

Goals and strategy of the pre-IND meeting: The objective of a 505(b)(2) pre-IND meeting is to gain input from the FDA and concurrence with the studies, clinical research plans, and chemistry, manufacturing and controls (CMC) strategy in order to minimize the number of new studies required for approval. Obtaining this input from the FDA can be vital to securing investments for many companies.

Number and type of required studies: The ability to use public data or previous FDA findings through the 505(b)(2) pathway may allow for programs to conduct 
bridging studies, preventing the need for some clinical or nonclinical studies traditionally required for a 505(b)(1).

Timing of CMC work: The clinical trial materials for Phase 1 studies should be representative of the commercial manufacturing process (including packaging) for a 505(b)(2) product. Generally, the three stability batches to be used for determination of shelflife are to be prepared at this time as well. As a result, a great deal of CMC work must be completed prior to initiation of studies, even for Phase 1.

Timing of studies: Due to the reliance on pre-existing data, clinical studies can be started simultaneously and developed in parallel. With the reliance of pre-existing data, a Phase 3 study can be initiated before completing all the Phase 1 studies and without having to conduct a Phase 2 study, which saves time and money. (7)

\section{Abbreviated New Drug applications}

These applications are termed "abbreviated" because they are generally not required to include preclinical (animal) and clinical (human) data to establish safety and effectiveness. (8)

\section{5 (j) Applications}

An ANDA is an application for a duplicate of a previously approved drug product that was submitted and approved under section 505(j) of the FD\&C Act. An ANDA relies on FDA's finding that the previously approved drug product, i.e., the reference listed drug (RLD), is safe and effective. An ANDA may contain certain types of differences from an RLD (e.g., a change approved in a suitability petition or other permissible differences, such as certain differences in inactive ingredients, labeling, or container closure systems), as long as investigations are not necessary to establish the safety or effectiveness of the drug product proposed in the ANDA.

An ANDA generally must contain information to show that the proposed generic product:

(1) is the same as the RLD with respect to the active ingredient(s), conditions of use, route of administration, dosage form, strength, and labeling (with certain permissible differences) and

(2) is bioequivalent to the RLD.

\section{Type of information to be included in ANDA}

An ANDA must also include sufficient information

(1) to demonstrate that the proposed product is bioequivalent to the RLD and

(2) to ensure the product's identity, strength, quality, and purity.

(3) additionally, ANDA may contain certain types of differences from an RLD (e.g., a change approved in a suitability petition or other permissible differences, such as certain differences in inactive ingredients, labeling, or container closure systems), as long as investigations are not necessary to establish the safety or effectiveness of the drug product proposed in the ANDA. (2)

\section{Key Considerations for Bioequivalence Studies}

For most products, the focus of bioequivalence studies is on the release of the drug substance from the drug product into the systemic circulation and specifically, on how the resulting systemic exposure profile of the test drug product compares to that of the RLD. Below, we discuss five considerations for a successful bioequivalence study.

\section{a. Appropriate Study Design}

For any drug, appropriate study design is critical to a successful development program and the ultimate approvability of the product. There are a myriad of study designs that can be employed depending upon the goals of the study, but in general, controlled studies may be categorized as either parallel (non-crossover) or crossover. In a parallel bioequivalence study, subjects are divided into two groups (A and $\mathrm{B}$ ) and receive only the treatment assigned to their group (either A or B; i.e., the RLD or the generic drug). This stands in contrast to the crossover study, in which one group of patients receives treatment $\mathrm{A}$ followed later by treatment $\mathrm{B}$ and the other group receives treatment B followed later by treatment A. Among the advantages of crossover studies is that they typically require fewer subjects than parallel studies and offer increased statistical power.

Within the basket of crossover studies, a study may be classified as either nonreplicate or replicate. Nonreplicate designs involve administering each treatment only once per subject, while replicate designs involve administration of one or both treatments at least twice per subject. The replicate design has the advantage of using fewer subjects than the nonreplicate design and is especially useful for highly variable drugs.

For bioequivalence studies, a replicate crossover design often represents an attractive alternative to other study designs.

\section{b. Parent Drug Versus Metabolites}

The foundation of a bioequivalence study is adequate sampling of appropriate body fluids for the presence of the drug. The parent drug in the dosage form should always be measured in these fluids, unless accurate assay quantification is not possible. In general, only parent drug levels are measured, rather than those of the metabolites, because the concentration-time profile of the parent drug is more sensitive to changes in formulation performance than that of a metabolite, which is more reflective of metabolite formation, distribution, and elimination.

That being said, primary metabolite(s), which are formed directly from the parent compound, should be measured if they are both.

- Formed substantially through pre-systemic metabolism (i.e., first-pass, gut wall, or gut lumen metabolism); and

- Contribute significantly to the safety and/or efficacy profile of the product.

This approach should be used for all drug products, including pro-drugs, with the drug expressed using 
confidence intervals (CI). Metabolite data can also be used to provide supportive evidence of a comparable therapeutic outcome.

\section{c. First Point $C_{\max }$}

Concentration-time profiles provide an indication of the absorption and elimination of a drug from the body fluid or tissue being assessed. When the first point of a concentration-time curve is the highest point, it raises significant questions of bias in the estimation of the maximum observed concentration $\left(\mathrm{C}_{\max }\right)$ because it is may be indicative of insufficient early sampling times. A carefully conducted pilot study can help avoid this problem by informing an adequately robust sampling schedule.

In the main bioequivalence study, collection of blood samples at a sufficiently early time point, often between 5 and 15 minutes after dosing, as well as at other appropriate time points (generally 2-5 collections) during the first hour post-dose is critical; indeed, FDA may not accept data from patients with insufficient early sampling, and this could detrimentally affect the robustness and interpretability of the pharmacokinetics analysis.

\section{d. Effects of Alcohol on Modified Release Drug Products}

In addition to appropriate study design and sampling schedules, consideration must be given to the desired release characteristics of the test drug and how these characteristics might impact the performance of the formulation when administered to patients outside of the controlled environment of a clinical trial. Importantly, the consumption of alcoholic beverages can affect the release of a drug substance from a modified release (MR) formulation. For example, the formulation can lose its modified release characteristics, leading to more rapid drug release and altered systemic exposure that can have deleterious effects on the safety and/or efficacy of the drug.

FDA recommends that Sponsors developing certain extended release solid oral dosage forms conduct in vitro studies to determine the potential for dose dumping in alcohol. Assessments using media containing various alcohol concentrations may be recommended and a human bioequivalence study in which the drug product is co-administered with alcohol may also be appropriate.

\section{e. Endogenous Compounds}

Endogenous compounds are drugs that are already present in the body either because the body produces them or they are present in the normal diet. Because these compounds are identical to the drug that is being administered, determining the amount of drug released from the dosage form and absorbed by each subject can be difficult.

Sponsors should measure baseline endogenous levels in the matrix of interest (e.g., blood or plasma), subtracting these levels from the total concentrations measured from each subject after the drug product has been administered. In this way, an estimate of the actual drug availability can be determined.
Depending upon whether the endogenous compound is naturally produced by the body or is present in the diet, the recommended approaches for determining bioequivalence are as follows:

- When the body produces the compound, multiple baseline concentrations should be determined in the time period before study drug administration. These baseline concentrations should be taken into account during the PK analysis in a manner consistent with the pharmacokinetic properties of the drug.

- When there is dietary intake of the compound, intake should be strictly controlled both before and during the study. Subjects should be housed at the clinic before the study and served standardized meals containing an amount of the compound similar to that in the meals to be served on the PK sampling day.

For both of these approaches, Sponsors should determine baseline concentrations for each dosing period. If a baseline correction results in a negative plasma concentration value, the value should be set equal to 0 before calculating the baseline-corrected area under the concentration-time curve (AUC). Pharmacokinetic and statistical analysis should be performed on both uncorrected and corrected data. Determination of bioequivalence should be based on the baselinecorrected data. (9)

\section{Petitioned ANDA}

A petitioned ANDA is a type of ANDA for a drug product that differs from the RLD in its dosage form, route of administration, strength, or active ingredient (in a product with more than one active ingredient) and for which FDA has determined, in response to a petition submitted under section 505(j)(2)(C) of the FD\&C Act (suitability petition), that studies are not necessary to establish the safety and effectiveness of the proposed drug product.

Certain differences between an RLD and a proposed generic drug product may be permitted in an ANDA if these differences are the subject of an approved suitability petition.

An applicant may submit a suitability petition to FDA requesting permission to submit an ANDA for a generic drug product that differs from an RLD in its route of administration, dosage form, or strength or that has one different active ingredient in a fixed combination drug product. (2)

No later than 90 days after the date a petition is submitted, FDA will approve or disapprove the petition.

FDA will approve a suitability petition unless, among other reasons, one of the following occurs:

- FDA determines that the safety and effectiveness of the proposed change from the RLD cannot be adequately evaluated without data from investigations that would be beyond the scope of what may be required for an ANDA. 
- A drug product is approved in a new drug application (NDA) for the change requested in the suitability petition.

- The suitability petition requests changes to a drug product that trigger the need for pediatric studies under the Pediatric Research Equity Act to assess the safety and efficacy of the drug product in a relevant pediatric subpopulation that would not be waived by FDA, which renders the proposed product ineligible for approval in an ANDA.

- FDA will refuse to receive an ANDA citing to a pending suitability petition (or to a suitability petition that was denied) because that ANDA would lack a legal basis for submission. (10)

\section{Patent and Exclusivity Protections:}

Table 1. Comparison of patent and exclusivity protections among different pathways $(6,11)$

\begin{tabular}{|c|c|c|c|}
\hline Application & $505(b)(1)$ & $505(b)(2)$ & $505(j)$ \\
\hline $\begin{array}{l}\text { Market } \\
\text { exclusivity }\end{array}$ & $\begin{array}{ll}\text { - } & \text { New Chemical Entity (NCE) } \\
\text { Exclusivity - } 5 \text { years } \\
\text { - } \quad \text { Orphan Drug Exclusivity } \\
\text { (ODE) - } 7 \text { years } \\
\text { - } \quad \text { Biologic Exclusivity - } 12 \\
\text { years } \\
\text { - } \quad \text { Pediatric Exclusivity (PED) - } \\
6 \text { months (added to any } \\
\text { existing exclusivity) } \\
\text { - Qualified Infectious Disease } \\
\text { Product (QDIP) Exclusivity - } \\
5 \text { years (added to any } \\
\text { existing exclusivity) }\end{array}$ & $\begin{array}{l}\text { - For new chemical entity (NCE): } \\
5 \text { years } \\
\text { - } \quad \text { orphan drug exclusivity (ODE): } \\
7 \text { years } \\
\text { - } \quad \text { other market exclusivity: } 3 \text { if } \\
\text { one or more of the clinical } \\
\text { investigations, other than } \\
\text { BA/BE studies, was essential to } \\
\text { approval of the application and } \\
\text { was conducted or sponsored by } \\
\text { the applicant } \\
\text { - Pediatric Exclusivity (PED) - } 6 \\
\text { months (added to any existing } \\
\text { exclusivity) }\end{array}$ & $\begin{array}{l}\text { Patent Challenge } \\
\text { Exclusivity - } 180 \text { days (if } \\
\text { it's the first generic } \\
\text { approved) and } 180 \text { days in } \\
\text { case of competitive } \\
\text { generic therapy (CGT) }\end{array}$ \\
\hline
\end{tabular}

\section{Submission through the appropriate Abbreviated approval pathway}

The differences allowed for suitability petition and 505(b)(2) application are same but ANDA filed through suitability petition can contain only those differences that do not need clinical evidence for efficacy and safety. In order to familiarize potential drug product developers with these abbreviated pathways, this article highlights criteria for submitting applications under the abbreviated approval pathways described in section 505(j) and 505(b)(2), identifies considerations to help potential applicants determine whether an application would be more appropriately submitted under section 505(j) or pursuant to section 505(b)(2) of the FD\&C Act, and provides direction to potential applicants on requesting assistance from FDA in making this determination.

\section{a. Regulatory considerations for ANDAS and 505(B)(2) applications}

\section{Duplicates}

- If a drug is a duplicate of a listed drug and eligible for approval under section 505(j), FDA will refuse to file a 505(b)(2) application.

- If FDA approves a pharmaceutical equivalent to a proposed product before a 505(b)(2) application is submitted, such that the proposed product would be a duplicate of that pharmaceutically equivalent drug product and eligible for approval under section 505(j) of the FD\&C Act, FDA will refuse to file the application as a 505(b)(2) application.

- However, if FDA approves a duplicate drug product after a 505(b)(2) application is submitted but before the 505(b)(2) application is approved, that application would remain eligible for approval as a 505(b)(2) application, and FDA would not require the applicant of the pending 505(b)(2) application to withdraw the application and submit an ANDA. (2)

\section{Petitioned ANDAs:}

- If the Suitability petition is applied for a drug product for which a pharmaceutical equivalent has been approved in an NDA, including, for example, a 505(b)(2) application that referenced the same listed drug named in the suitability petition, then it will not be approved. In this case, the ANDA applicant should instead refer to the approved pharmaceutical equivalent designated by the Agency as the RLD as the basis for its ANDA.

- If, after approval of a petition and before approval of an ANDA submitted pursuant to the approved petition, a drug product is approved in an NDA for the change described in the petition, the petition and the listed drug identified in the petition can no longer be the basis for ANDA submission, irrespective of whether FDA has withdrawn approval of the petition. A person seeking approval for such drug product must submit a new ANDA that identifies the pharmaceutically equivalent reference listed drug as the basis for ANDA submission and comply with applicable regulatory requirements. (2)

\section{c. Bundling}


In some circumstances, an applicant may seek approval for multiple drug products containing the same active ingredient(s) when some of these products would qualify for approval under the section 505(j) pathway and some would qualify for approval under the 505(b)(2) pathway. In these circumstances, FDA has permitted an applicant to submit a single 505(b)(2) application for all such multiple drug products that are permitted to be bundled in a single NDA. (2)

\section{b. Differences in scientific considerations for ANDAs and 505(b)(2) applications}

Table 2. Differences between ANDAs and 505(b)(2) applications $(2,6,12,13)$

\begin{tabular}{|c|c|c|}
\hline Parameters & ANDAs & 505(b)(2) APPLICATIONS \\
\hline $\begin{array}{l}\text { Safety \& } \\
\text { efficacy }\end{array}$ & $\begin{array}{l}\text { No preclinical or clinical data are needed however, } \\
\text { under certain circumstances, data from limited } \\
\text { confirmatory testing to show that the characteristics } \\
\text { that make the proposed drug product different from the } \\
\text { listed drug do not alter its safety and effectiveness } \\
\text { may be accepted in a petition or as additional data to } \\
\text { be included in an ANDA resulting from an approved } \\
\text { petition }\end{array}$ & $\begin{array}{l}\text { preclinical or clinical data are needed to } \\
\text { support safety and effectiveness of the } \\
\text { requested change }\end{array}$ \\
\hline $\begin{array}{l}\text { Active } \\
\text { ingredient }\end{array}$ & $\begin{array}{l}\text { proposed generic drug product demonstrate that it is } \\
\text { the same as the RLD with respect to active } \\
\text { ingredient(s) } \\
\text { If the active ingredient cannot be demonstrated to be } \\
\text { the same as the active ingredient in the RLD by using } \\
\text { the information and data that may be submitted in } \\
\text { connection with an ANDA, the drug product should } \\
\text { not be submitted for approval in an ANDA. }\end{array}$ & $\begin{array}{l}\text { Change in an active ingredient such as a } \\
\text { different salt, ester, complex, chelate, } \\
\text { clathrate, racemate, or enantiomer of an } \\
\text { active ingredient in a listed drug containing } \\
\text { the same active moiety to be submitted as } \\
505 \text { (b)(2). } \\
\text { An application for a change in one of the } \\
\text { active ingredients of an approved } \\
\text { combination product for another active } \\
\text { ingredient that has or has not been previously } \\
\text { approved to be submitted as } 505 \text { (b)(2). }\end{array}$ \\
\hline Formulation & $\begin{array}{l}\text { The active ingredient(s) in a proposed ANDA be the } \\
\text { same as the active ingredient(s) in the RLD, certain } \\
\text { differences in inactive ingredients are permissible. } \\
\text { For products for certain routes of administration, to } \\
\text { qualify for submission as an ANDA: } \\
\text { Parenteral drug products: same inactive ingredients } \\
\text { and in the same concentrations as the RLD (Q1/Q2 } \\
\text { same) and specific qualitative and quantitative changes } \\
\text { from the RLD formulation are permitted for exception } \\
\text { excipients (i.e., preservatives, buffers, and } \\
\text { antioxidants) } \\
\text { Ophthalmic drug products: (Q1/Q2 same) and } \\
\text { specific qualitative and quantitative changes from the } \\
\text { RLD formulation are permitted for exception } \\
\text { excipients (i.e., preservatives, buffers, substances to } \\
\text { adjust tonicity, or thickening agents). FDA has } \\
\text { determined that, for qualitative or quantitative } \\
\text { deviations from the RLD may raise a concern } \\
\text { regarding safety or efficacy changes and hence require } \\
\text { an appropriate in vivo bioequivalence study or other } \\
\text { studies. } \\
\text { Otic drug products generally should be Q1/Q2 same } \\
\text { as the RLD with respect to all of their inactive } \\
\text { ingredients. }\end{array}$ & $\begin{array}{l}\text { An applicant should consider submitting a } \\
505(\mathrm{~b})(2) \text { application, if the proposed drug } \\
\text { product contains changes to its formulation } \\
\text { that are not permissible in an ANDA. } \\
\text { For example, } \\
\text { a proposed parenteral drug product that } \\
\text { contains an additional inactive ingredient not } \\
\text { present in the RLD that cannot be considered } \\
\text { an exception excipient would not be } \\
\text { permitted in an ANDA but may be submitted } \\
\text { in a 505(b)(2) application. } \\
\text { Similarly, a proposed drug product that } \\
\text { contains a novel excipient, e.g., an excipient } \\
\text { that has not been used in an FDA-approved } \\
\text { drug product, the safety of which cannot be } \\
\text { established without clinical testing, would } \\
\text { also not be permitted in an ANDA but may } \\
\text { be submitted in a 505(b)(2) application. }\end{array}$ \\
\hline $\begin{array}{l}\text { Bioequivalenc } \\
\text { e and/or } \\
\text { bioavailability }\end{array}$ & $\begin{array}{l}\text { An ANDA must contain information to show that the } \\
\text { proposed drug product is bioequivalent to the RLD. }\end{array}$ & $\begin{array}{l}\text { An application for a proposed drug product } \\
\text { where the rate and/or extent of absorption } \\
\text { exceed, or are otherwise different from, the } \\
505(\mathrm{j}) \text { standards for bioequivalence may be } \\
\text { submitted under the } 505(\mathrm{~b})(2) \text { pathway and } \\
\text { may require studies to show the safety and } \\
\text { efficacy of the proposed product at the } \\
\text { different rate and/or extent of delivery. } \\
\text { Note: 505(b)(2) application is not } \\
\text { appropriate for a drug product that should } \\
\text { have been submitted under the ANDA }\end{array}$ \\
\hline
\end{tabular}




\begin{tabular}{|c|c|c|}
\hline & & $\begin{array}{l}\text { pathway but failed to meet all of the } 505(\mathrm{j}) \\
\text { standards (e.g., the proposed drug product is } \\
\text { a duplicate of a listed drug but is } \\
\text { unintentionally less bioavailable and fails to } \\
\text { demonstrate bioequivalence to the listed } \\
\text { drug). }\end{array}$ \\
\hline $\begin{array}{l}\text { Conditions of } \\
\text { use }\end{array}$ & $\begin{array}{l}\text { ANDA must include a statement that the conditions of } \\
\text { use prescribed, recommended, or suggested in the } \\
\text { labeling for the proposed drug product have been } \\
\text { previously approved for the RLD. } \\
\text { Note, FDA will not refuse to approve an ANDA whose } \\
\text { labeling excludes conditions of use approved for the } \\
\text { RLD that may be omitted from the proposed ANDA } \\
\text { labeling because of patents or exclusivity. }\end{array}$ & $\begin{array}{l}\text { An application for a not previously approved } \\
\text { indication for a listed drug. }\end{array}$ \\
\hline Labeling & $\begin{array}{l}\text { An ANDA must contain information to show that the } \\
\text { labeling proposed for the new drug is the same as the } \\
\text { labeling approved for the [RLD] except for changes } \\
\text { required because of differences approved under a } \\
\text { [suitability petition] or because the new drug and the } \\
\text { [RLD] are produced or distributed by different } \\
\text { manufacturers } \\
\text { For e.g. differences in the products' expiration dates, } \\
\text { formulation, bioavailability, or pharmacokinetics; } \\
\text { labeling revisions made to comply with current FDA } \\
\text { labeling guidelines or guidance; or the omission of an } \\
\text { indication or other aspect of labeling protected by } \\
\text { patent or exclusivity may be appropriate }\end{array}$ & $\begin{array}{l}\text { If the differences between the products are } \\
\text { such that they would require investigations to } \\
\text { establish the safety or effectiveness of the } \\
\text { proposed product or necessitate such } \\
\text { significant labeling differences that the } \\
\text { labeling no longer satisfies the "same" } \\
\text { labeling requirement, the proposed drug } \\
\text { product should be submitted under section } \\
\text { 505(b) of the FD\&C Act. } \\
\text { For example, an ANDA is not appropriate if } \\
\text { the proposed drug product would have a new } \\
\text { indication or a new dosing regimen as } \\
\text { compared to the RLD (e.g., a proposed } \\
\text { product would be administered once daily } \\
\text { even though the RLD is labeled for } \\
\text { administration twice daily). }\end{array}$ \\
\hline
\end{tabular}

\section{c. Requesting Assistance from FDA}

One of the most important aspects of any drug development program is the stream of interactions with regulatory authorities like the US Food and Drug Table 3. Requesting Assistance from FDA (2)
Administration (FDA). These interactions can take many forms, from formal submissions to phone calls, face-toface meetings, or emails.

\begin{tabular}{|l|l|}
\hline \multicolumn{1}{|c|}{ Type of application } & \multicolumn{1}{c|}{ Assistance discipline from FDA } \\
\hline New drug applications & $\begin{array}{l}\text { NDAs are typically regulated by FDA's Center for Drug } \\
\text { Evaluation and Research (CDER) }\end{array}$ \\
\hline $\begin{array}{l}\text { Regarding questions about qualification of application } \\
\text { as an ANDA }\end{array}$ & $\begin{array}{l}\text { Office of Generic Drugs (OGD) through controlled } \\
\text { correspondence or request a pre-ANDA meeting* }\end{array}$ \\
\hline $\begin{array}{l}\text { Suitability petition } \\
\text { Regarding questions about submission of an application } \\
\text { through the 505(b)(2) pathway }\end{array}$ & \begin{tabular}{l} 
Oivision of Dockets Management \\
\hline
\end{tabular}
\end{tabular}

* Controlled correspondence is appropriate if an applicant has a specific and targeted inquiry about the generic drug development process. A pre-ANDA meeting is appropriate for a prospective applicant seeking a dialogue with the Agency on a particular matter that would fall outside the scope of controlled correspondence.

\section{Conclusion}

A lack of familiarity with the regulatory pathway may result in an unnecessarily larger development program than needed. This paper will help potential drug product developers to familiarize with different approval pathways for drug products under the FD\&C Act NDAs pursuant to section 505 (b)(1) and 505(b)(2) of the FD\&C Act and ANDAs under section 505(j) of the FD\&C Act, petitioned ANDAs under section 505(j)(2)(C) of the FD\&C Act - the types of data and information that are permitted to support approval under those pathways.
The NDA is a formal request made by a sponsor to market a new drug in the United States. NDAs are typically regulated by FDA's Center for Drug Evaluation and Research (CDER). Data collected during the IND phase of the development program will become part of the NDA. The primary responsibilities of the FDA during development of an investigational product include minimizing the safety risk to clinical trial participants and helping to support the collection of meaningful clinical data. Data collected during the IND phase of the development program will become part of the NDA. However, the NDA is much more 
comprehensive than the IND and is expected to provide very detailed information about the drug.

The 505(b)(2) development pathway provides far more efficient drug development for follow-on products by allowing reliance on certain external data and information for the NDA. Understanding how to bridge your drug to an approved drug and what types of information are appropriate to use is critical to getting your drug approved.

Sponsors interested in seeking FDA approval of a generic drug should consider several factors when planning their bioequivalence study. Careful consideration of the appropriate study design, sampling schedule, desired release characteristics, and any confounding by endogenous compounds will go a long way toward promoting a successful development program.

This paper also highlights criteria for submitting applications under the abbreviated approval pathways described in section 505(j) and 505(b)(2), identifies considerations to help potential applicants determine whether an application would be more appropriately submitted under section 505(j) or pursuant to section 505(b)(2) of the FD\&C Act, and provides direction to potential applicants on requesting assistance from FDA in making this determination.

\section{Acknowledgements}

The authors are very much thankful to Isazi Pharma and Techno Consultancy for their support and constant encouragement.

Financial Disclosure statement: The author received no specific funding for this work.

\section{Conflict of Interest}

The authors declare that there is no conflict of interest regarding the publication of this article.

\section{References}

1. Brandon Burch Nuventra's Pharmascience Blog [Internet]. Durham, NC: Brandon Burch; 2020 Apr 01 [cited $2021 \mathrm{Feb} 02$ ]. Available from: https://www.nuventra.com/resources/blog/505b1-505b2pathways-for-new-drugs/

2. USFDA. Guidance for Industry: Determining Whether to Submit an ANDA or a 505(b)(2) Application, Draft Guidance; 2017 Oct.

3. Danielle Moffett Nuventra's Pharmascience Blog [Internet]. Durham, NC: Danielle Moffett; 2020 Feb 05 [cited $2021 \mathrm{Feb}$ 05]. Available from:

https://www.nuventra.com/resources/blog/quick-guide-tofda-drug-application-types/

4. Brandon Burch Nuventra's Pharmascience Blog. IND requirements exemptions [Internet]. Durham, NC: Brandon Burch; 2018 Jun 20 [cited 2021 Feb 05]. Available from: https://www.nuventra.com/resources/blog/indrequirements-exemptions/

5. 505 (b)(2) Regulatory Pathway for New Drug Approvals, November 1, 2017 by Ryan Chandanais, MS, CPhT [Internet]. Pharmacytimes; 2017 Nov 01 [cited 2021 Feb 07]. Available from: https://www.pharmacytimes.com/view/505-b2-regulatorypathway-for-new-drug-approvals-

6. USFDA. Guidance for Industry: Applications Covered by Section 505(b)(2), Draft Guidance; 1999 Oct.

7. Michael J. Lamson Nuventra's Pharmascience Blog. What is 505b2 [Internet]. Durham, NC: Michael J. Lamson; 2021 Mar 10 [cited $2021 \mathrm{Feb}$ 09]. Available from:

https://www.nuventra.com/resources/blog/what-is-505b2/

8. USFDA. ANDA [Internet]. US: Food \& Drug Administration; 2019 May 22 [cited 2021 Feb 09] Available from: https://www.fda.gov/drugs/typesapplications/abbreviated-new-drug-application-anda

9. Brandon Burch Nuventra's Pharmascience Blog [Internet]. Durham, NC: Brandon Burch; 2018 Jan 10 [cited $2021 \mathrm{Feb} 06]$. Available from:

https://www.nuventra.com/resources/blog/bioequivalencestudies-support-generic-drugs/

10. Manual of Policies And Procedures, Office Of Generic Drugs, ANDA Suitability Petitions: MAPP 5240.5 Rev. 2

11. Brandon Burch Nuventra's Pharmascience Blog. Types of marketing exclusivity [Internet]. Durham, NC: Brandon Burch; 2019 Aug 28 [cited 2021 Feb 07] Available from: https://www.nuventra.com/resources/blog/types-ofmarketing-exclusivity/

12. M SK, Katamreddy JD, P JR. A review on ANDA submission requirements for Generic drugs: "Paragraph IV certification" as per FDA CDER guidelines. Int J Drug Reg Affairs [Internet]. 2018 Sep15 [cited 2021 Jun 15]; 6(3):5-12. Available from:

http://ijdra.com/index.php/journal/article/view/260

13. Shah S, Badjatya JK. Preliminary requirement for filing application in US. Int J Drug Reg Affairs [Internet]. 2018 Dec 20 [cited 2021 Jun 15];6(4):1-8. Available from: http://ijdra.com/index.php/journal/article/view/276 